\title{
Pengaruh Media Film Terhadap Keterampilan Menulis Narasi Pada Mata pelajaran Bahasa Indonesia Pada Siswa Kelas V SD 02 Pagi Cipayung
}

\author{
Santhi Pertiwi ${ }^{1}$, Kitza Valletta Kolen ${ }^{2}$ \\ Fakultas Keguruan dan Ilmu Pendidikan Universitas Mohammad Husni Thamrin \\ Correspondence author : Santhi Pertiwi, email ; antique_sp11@yahoo.com \\ DOI: https://doi.org/10.37012/jipmht.v4i1.196
}

\begin{abstract}
ABSTRAK
Latar belakang yakni keterbatasan media pembelajaran menulis narasi efektif menjadi kendala yang dihadapi guru. Guru tidak bisa menentukan media seperti apa yang disenangi siswa agar siswa mampu mencapai tujuan pembelajaran, sehingga siswa sulit menemukan ide untuk dituangkan ke dalam tulisan, siswa pun sulit memusatkan konsentrasinya karena kurangnya pengetahuan dan frekuensi berlatih dalam menulis narasi. Keunggulan-keunggulan media film yaitu cocok untuk mengajarkan keterampilan termasuk di dalamnya adalah keterampilan menulis narasi, mempertinggi minat siswa, membantu mengatasi ketidak aktifan siswa, merangsang diskusi kelas, serta membantu siswa untuk menemukan gagasan dalam mengawali kegiatan mengarang. Tujuan penelitian adalah untuk menganalisis pengaruh Media Film terhadap Keterampilan Menulis Narasi.Penelitian dilaksanakan di SD 02 Pagi Cipayung, sampel siswa kelas V pada semester II tahun pelajaran 2017/2018. Sampel diambil dengan menggunakan Teknik Simple Random Sampling. Pengumpulan data dilakukan dengan menggunakan tes keterampilan menulis narasi, kemudian dihitung normalitas data menggunakan liliefors dan homogenitas kelas menggunakan barlet. Hasil pengujian normalitas dan homogenitas menunjukkan bahwa data berdistribusi normal dan kedua kelas homogen. Selanjutnya dianalisa dengan uji t. Hasil penghitungan uji-t, diperoleh harga thitung sebesar 1,92. Harga ttabel pada taraf signifikansi $\alpha=0,05$ dan $\mathrm{dk}=31$ adalah 1,70 . Oleh karena harga thitung lebih besar dari pada ttabel $(1,92>1,70)$, maka hipotesis nol ditolak dan hipotesis kerja diterima. Dengan demikian, Media Film berpengaruh secara signifikan terhadap ketermapilan menulis narasi siswa kelas V sekolah dasar.
\end{abstract}

Kata kunci : menulis narasi, media film, keterampilan menulis narasi siswa.

\begin{abstract}
The background, namely the limitations of effective narrative writing learning media is an obstacle faced by teachers. The teacher cannot determine what kind of media students like so that students are able to achieve the learning objectives, so students find it difficult to find ideas to be written into writing, students also find it difficult to focus their concentration due to lack of knowledge and frequency of practice in narrative writing. The advantages of film media are that it is suitable for teaching skills including narrative writing skills, heightening student interest, helping to overcome student inactivity, stimulating class discussion, and helping students to find ideas in initiating writing activities. The purpose of this study was to analyze the effect of Film Media on Narrative Writing Skills.

The study was conducted at SD 02 Pagi Cipayung, a sample of fifth grade students in the second semester of the 2017/2018 school year. Samples were taken using the Simple Random Sampling Technique. Data collection was carried out using narrative writing skills tests, then normality of data was calculated using liliefors and class homogeneity using barlets. The results of normality and homogeneity tests show that the
\end{abstract}


data are normally distributed and both classes are homogeneous. Then analyzed with $t$ test. The t-test results obtained a t-count of 1.92. The price of the table at the significance level $\alpha=0.05$ and $d k=31$ is Because the price of $t$ is greater than t table (1.92> 1.70), the null hypothesis is rejected and the working hypothesis is accepted. Thus, Film Media significantly influences the narrative writing skills of fifth grade elementary school students.

Keyword: narrative writing, film media, students' narrative writing skills.

\section{PENDAHULUAN}

Pada tingkatan sekolah dasar terdapat mata pelajaran bahasa Indonesia pembelajaran bahasa Indonesia ini berfungsi untuk meningkatkan kemampuan berkomunikasi siswa baik secara lisan maupun tulisan. Namun kenyataannya, pembelajaran disekolah sering kali mengalami kesulitan dalam pelajaran bahasa Indonesia. Padahal bahasa Indonesia merupakan bahasa ilmu pengetahuan yang mempunyai peranan penting dalam memajukan daya pikir manusia.

Pengajaran bahasa Indonesia mempunyai empat aspek keterampilan berbahasa yaitu keterampilan menulis, keterampilan membaca, keterampilan menyimak, keterampilan berbicara. Salah satu keterampilan yang harus dikuasai siswa yaitu keterampilan menulis. Dengan memiliki keterampilan menulis siswa dapat mengungkapakan gagasan, pendapat, serta perasaan melalui tulisan.

Menulis merupakan aktivitas yang tidak dapat dipisahkan dari kegiatan sehari - hari setiap orang. Menulis dilakukan salah satunya oleh para akademis, seperti siswa ataupun mahasiswa, kegiatan menulis banyak dilakukan baik di rumah maupun di sekolah. Kegiatan menulis yang dilakukan dapat berupa merangkum, menulis agenda, mencatat materi, maupun menulis narasi. Wawancara yang dilakukan peneliti kepada beberapa guru, didapat bahwa pada mata pelajaran bahasa Indonesia terutama dalam keterampilan menulis masih banyak siswa siswa sulit untuk menuangkan ide atau gagasanya ke dalam tulisan. Guru perlu melakukan kegiatan pembelajaran yang menarik dan kreatif, karena kemampuan menulis sangat penting untuk dikuasai oleh setiap orang, khususnya siswa, yang banyak melibatkan aktivitas menulis dalam kegiatan pembelajaran.

Rendahnya hasil belajar bahasa Indonesia siswa dapat diartikan kurang berhasilnya proses pembelajaran. Faktor yang menyebabkan rendahnya hasil belajar bahasa Indonesia dalam kemampuan menulis narasisalah satunya yaitu minimnya variasi dalam pembelajaran melalui penggunanan media yang digunakan oleh guru. Sehingga membuat siswa kurang memperhatikan saat kegiatan belajar mengajar berlangsung. Siswa merasa kegiatan belajar mengajar yang berlangsung kurang menarik dan membosankan. Siswa menjadi sulit untuk menemukan ide atau gagasan untuk dituangkan dalam kegiatan menulis narasi. 
Sebagai tindak lanjut dari masalah yang dikemukakan di atas, maka digunakan suatu medi, media adalah perantara atau alat yang dapat dijadikan perantara dalam penyampaian pesan dari pengirim menuju penerima pesan. manfaat media sebagai berikut

a) menjelaskan pesan agar tidak terlalu verbalistis,

b) menimbulkan gairah belajar, interaksi lebih langsung antara siswa dengan sumber belajar,

c) memungkinkan anak belajar mandiri sesuai dengan bakat dan kemampuan visual, auditori dan kinestetiknya,

d) memberi rangsangan sama, mempersamakan pengalaman dan menimbulkan persepsi yang sama,

e) Proses pembelajaran mengandung lima komponen komunikasi, guru (komunikator)bahan pembelajaran, media pembelajaran, siswa (komunikan), dan tujuan pembelajaran.

Jadi media pembelajaran adalah segala sesuatu yang dapat digunakan untuk menyalurkan pesan (bahan pembelajaran), sehingga dapat merangsang perhatian, minat, pikiran dan perasaan siswa dalam kegiatan belajar untuk mencapai tujuan pembelajaran. empat faktor yang perlu dipertimbangkan dalam pemilihan media, yaitu

(a) ketersediaan sumber setempat,

(b) ketersediaan dana, tenaga dan fasilitas setempat,

(c) faktor yang menyangkut keluwesan, kepraktisan dan ketahanan media,

(d) efektivitas biayanya

dalam waktu yang panjang Apabila keempat faktor dapat terpenuhi, maka media layak digunakan dalam kelas. Untuk mengasah keterampilan menulis siswa, maka siswa perlu dibiasakan dengan kegiatan menulis. Pembiasaan ini dapat dilakukan dengan cara meminta siswa untuk menuliskan peristiwa- peristiwa yang mereka alami sendiri. Siswa dibiasakan untuk menceritakan peristiwa yang telah mereka alami kepada orang lain dalam bahasa tulis. Salah satu jenis karangan yang sesuai untuk membiasakan siswa dalam kegiatan menulis adalah karangan narasi informasional atau narasi ekspositoris. Hal tersebut dikarenakan karangan narasi informasional atau narasi ekspositoris merupakan jenis karangan yang bertujuan hanya memberikan informasi saja terhadap pembaca dan di dalamnya tidak mengandung kata- kata. yang bermakna konotasi sehingga tidak menyulitkan siswa dalam membuat karangan narasi tersebut. Hal tersebut berarti bahwa, karangan narasi informasional atau narasi ekspositoris dapat dibuat berdasarkan peristiwa-pristiwa yang telah terjadi atau bahkan dialami sendiri oleh siswa.

Anak pada rentang usia 7-11 tahun atau dalam hal ini usia siswa kelas V SD pada umumnya berada pada tahap perkembangan kognitif operasional konkret yang baru mampu berpikir sistematis mengenai bendabenda dan peristiwa-peristiwa yang bersifat konkret. Untuk mengatasi masalah tersebut, maka diperlukan semacam stimulus yang bertujuan untuk merangsang siswa untuk mengawali 
Kegiatan menulis. Pemberian stimulus tersebut dapat dilakukan melalui media pembelajaran yang digunakan dalam pembelajaran keterampilan menulis. Media pembelajaran sendiri ada banyak sekali macamnya baik yang bersifat audio, visual, maupun audiovisual. Pada dasarnya, karangan narasi merupakan salah satu jenis karangan yang menceritakan suatu peristiwaperistiwa yang terjadi secara runtut dalam suatu kesatuan waktu. Oleh karena itu, dalam pemberian stimulus berupa penggunaan media pembelajaran hendaknya menggunakan media yang tepat. Media film strip merupakan salah satu media pembelajaran yang tepat digunakan dalam pembelajaran keterampilan menulis narasi. merupakan media yang memproyeksikan gambar-gambar diam, yang mana gambargambar diam yang diproyeksikan tersebut merupakan gambar-gambar yang memiliki urutan yang kronologis. Gambar-gambar diam tersebut juga dilengkapi dengan deskripsi yang menerangkan peristiwa-peristiwa yang terjadi. Sehingga, apabila media film digunakan dalam pembelajaran keterampilan menulis narasi maka siswa akan dapat lebih mudah dalam menulis narasi Hal tersebut dikarenakan media film.

Berdasarkan latar belakang yang di atas, maka diidentifikasi masalah dari penelitian ini antara lain:

(a) Mengapa pembelajaran bahasa Indonesia pada kemampuan menulis narasi menurun?

(b) Bagaimana mengatasi pembelajaran menulis yang terkesan membosankan?

(c) Apakah media film berpengaruh terhadap peningkatan keterampilan menulis narasi?

\section{METODE}

Berdasarkan tujuan penelitian, metode yang digunakan adalah metode Kuasi eksperimen. Desain penelitian yang digunakan adalah bentuk Post test only control design. Seperti terlihat pada bagan berikut:

\section{Post test only control design :}

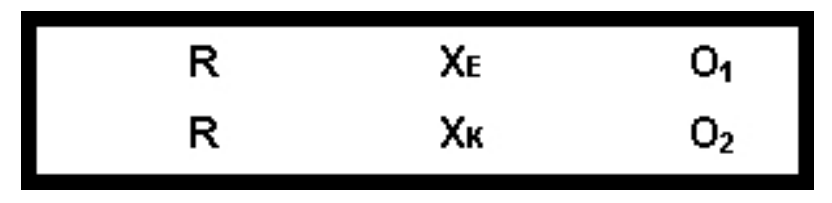

Keterangan:

$\mathrm{R}=$ Random

$\mathrm{XE}=$ Perlakuan yang diberikan kepada kelompok eksperimen (media film) $\mathrm{XK}=$ Perlakuan yang diberikan kepada kelompok kontrol (media gambar)

$\mathrm{O} 1$ = Hasil pengukuran kelompok eksperiment $\mathrm{O} 2$

= Hasil pengukuran kelompok kontrol 
Mengacu pada desain penelitian tersebut, peneliti menempatkan ke dalam dua kelompok (kelas) yang dipilih secara random, yaitu kelas eksperimen yang akan diberi perlakuan dengan menggunakan media film sedangkan kelas kontrol diberi perlakuan menggunakan media gambar.

Tabel 3.1. Persamaan dan Perbedaan Perlakuan yang Diberikan Terhadap Kelas Eksperimen dan Kelas

Kontrol

\begin{tabular}{lll}
\hline $\begin{array}{l}\text { Komponen } \\
\text { Pembelajaran }\end{array}$ & $\begin{array}{l}\text { Kelas Eksperimen } \\
\text { Media Film }\end{array}$ & $\begin{array}{l}\text { Kelas Kontrol } \\
\text { Media } \\
\text { Konvensional }\end{array}$ \\
\hline Pengajar & Peneliti & Peneliti \\
\hline Materi & Film yang sama & Cerita \\
\hline Pertemuan & Pendidikan & 2 x pertemuan \\
\hline Metode & 2xertemuan & Ceramah \\
& $\begin{array}{l}\text { Tanya jawab Diskusi } \\
\text { kelompok }\end{array}$
\end{tabular}

Media, Alat dan Sumber
Belajar

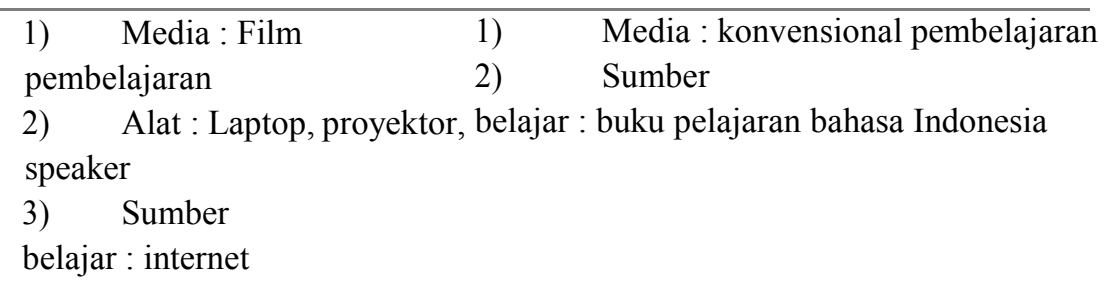

\section{Populasi dan Teknik Pengambilan Sampel}

Populasi merupakan wilayah generalisasi yang terdiri atas obyek atau subyek yang mempunyai kualitas dan karekteristik tertentu yang di tetapkan peneliti untuk dipelajari dan kemudian ditarik kesimpulannya. Jadi hasil penelitian yang dilakukan pada sampel penelitian mewakili hasil penelitian pada seluruh populasi.

\section{Populasi}

a) Populasi Target dalam penelitian ini adalah seluruh siswa kelas V di SD Negeri wilayah Cipayung Jakarta Timur.

b) Populasi Terjangkau adalah seluruh siswa kelas V SD Negeri di Wilayah Cipayung, Jakarta Timur tahun ajaran 2017 - 2018 yang memiliki kelas paralel. 


\section{Sampel}

Teknik pengambilan sampel yang digunakan dalam penelitian ini adalah teknik Simple Random Sampling, yaitu memilih salah satu atau beberapa kelompok secara sederhana. Teknik Pengambilan sampel dengan random dalam penelitian ini ditempuh dengan cara undian atau kocokan. Berdasarkan populasi target yang dimiliki adalah semua SD Negeri pagi yang berada di wilayah Cipayung Jakarta Timur yang memiliki kelas paralel, yang terdiri dari 5 SD Negeri pagi yaitu SDN 01 Pagi, SDN 03 Pagi, SDN 02 Pagi, SDN 04 Pagi, SDN 05 Pagi. Dari 5 SD Negeri tersebut dilakukan pengundian atau pengocokan, maka terpilih satu SD yaitu SDN Cipayung 02 Pagi yang memiliki kelas paralel. Kemudian dilakukan pengocokan untuk menentukan kelas kontrol dan kelas eksperimen, dari hasil pengocokan maka terpilihlah kelas V A sebagai kelas eksperimen dan kelas V B sebagai kelas kontrol. Pengumpulan data dilakukan dengan menggunakan tes keterampilan menulis narasi, kemudian dihitung normalitas data menggunakan liliefors dan homogenitas kelas menggunakan barlet. Hasil pengujian normalitas dan homogenitas menunjukkan bahwa data berdistribusi normal dan kedua kelas homogen. Selanjutnya dianalisa dengan uji t.

HASIL \& PEMBAHASAN (Times New Roman 12 point, Bold, spasi 1,5)

\section{A. Uji Persyaratan Analisis}

1 . Uji Normalitas Posttest

Uji normalitas keterampilan menulis narasi dilakukan dengan menggunakan liliefors.

Hasil perhitungan uji normalitas posttest dapat terlihat pada tabel di bawah ini:

Tabel 4.3. Uji Normalitas Posttest Kelas Eksperimen dan Kelas Kontrol

\begin{tabular}{ccccc}
\hline No. & Kelas & $\begin{array}{c}\text { L } \\
\text { hitung }\end{array}$ & $\begin{array}{c}\text { L } \\
\text { tabel }\end{array}$ & Kesimpulan \\
\hline 1. & Eksperimen & 0,116 & 0,157 & Normal \\
\hline 2. & Kontrol & 0,061 & 0,157 & Normal \\
\hline
\end{tabular}

Harga $\mathrm{L}_{\text {tabel }}$ pada taraf signifikansi $\alpha=0,05$ untuk $\mathrm{n}=32$ adalah 0,157 dan karena kedua harga $\mathrm{L}_{\text {hitung }}$ pada hasil pengujian normalitas tersebut lebih kecil dari $\mathrm{L}_{\text {tabel }}(0,116$ dan 0,157$)$, maka dapat disimpulkan bahwa data posttest pada kelas eksperimen maupun kelas kontrol berdistribusi normal. 
2.

Uji Homogenitas

Uji homogenitas untuk gain (beda) kedua kelas menggunakan uji Barlet. Hasil perhitungan uji homogenitas dengan uji Barlet dapat terlihat pada tabel di bawahini:

Tabel 4.4 Uji Homogenitas Kelas Eksperimen dan Kontrol

No.

$\begin{array}{cccc}\begin{array}{r}\text { Sumber } \\ \text { Varian }\end{array} & \mathbf{X} & \mathbf{X} & \text { Kesimpulan } \\ \text { hitung } & \text { tabel } & \end{array}$

Varian hitung tabel

$\begin{array}{lllll}1 . & \text { Kelas } & & \\ 1,24 & 7,81 & \text { Homogen }\end{array}$

Eksperimen dan Kelas Kontrol

Berdasarkan hasil perhitungan diperoleh harga $X$.Hitung sebesar 1,24 sedangkan harga $X_{\text {.tabel }}$ pada taraf signifikansi $\alpha=0,05$ dengan derajat.

\section{B. Pengujian Hipotesis dan Pembahasan}

\section{Pengujian Hipotesis}

Pengujian hipotesis dilakukan untuk mengetahui apakah hipotesis nol ditolak atau sebaliknya. Sebelum dilakukan uji hipotesis, terlebih dahulu dilakukan pengujian persyaratan analisis yang meliputi uji normalitas dan uji homogenitas kelompok kelas eksperimen maupun kelas kontrol. Berdasarkan hasil perhitungan kedua pengujian tersebut diketahui bahwa kedua kelompok berdistribusi normal dan memiliki varian yang homogen sehingga dapat dilanjutkan untuk pengujian hipotesis dengan uji-t.

Tabel 4.5 Uji Hipotesis Kelas Eksperimen dan Kontrol

\begin{tabular}{ccccc}
\hline No. & Kelas & t hitung & t tabel & Kesimpulan \\
\hline 1. & $\begin{array}{c}\text { Eksperimen } \\
\text { dan } \\
\text { Kontrol }\end{array}$ & 1,92 & 1,70 & $\mathrm{H}_{1}$ diterima \\
& & & $\mathrm{H}_{\mathrm{O} \text { ditolak }}$ \\
\hline
\end{tabular}

Berdasarkan hasil perhitungan uji-t diperoleh harga $t$ hitung dan $d k=31$ sebesar 1,92. Sedangkan harga $t$ tabel pada taraf signifikansi $\alpha=0,05 \mathrm{dan} \mathrm{dk}=31$ adalah sebesar 1,70. Oleh 
(H1) diterima dan hipotesis nol (H0) ditolak.

\section{KESIMPULAN DAN REKOMENDASI}

Kesimpulan Hasil perhitungan menunjukkan bahwa thitung sebesar 1,92 sedangkan harga ttabel pada taraf signifikansi $\alpha=0,05$ adalah sebesar 1,70. Oleh karena harga thitung lebih besar daripada harga tabel $(1,92>1,70)$, maka artinya hipotesis kerja (H1) diterima dan hipotesis nol (H0) ditolak.

Berdasarkan hasil penelitian dapat disimpulkan bahwa keterampilan menulis narasi siswa yang menggunakan Media Film lebih tinggi daripada keterampilan menulis narasi siswa yang menggunakan pembelajaran konvensional pada mata pelajaran Bahasa Indonesia.

Kesimpulan diatas memberikan suatu pengertian bahwa pembelajaran Bahasa Indonesia dengan menggunakan Media Film dapat berpengaruh terhadap keterampilan menulis narasi siswa Sekolah Dasar. Keberhasilan siswa dalam belajar tidak terlepas dari kemampuan guru dalam merencanakan dan menyampaikan materi pelajaran serta memilih media pembelajaran yang dapat menumbuhkan minat dan motivasi belajar siswa sehingga meningkatkan keterampilan menulis narasi siswa khususnya di dalam pembelajaran Bahasa Indonesia.

\section{A. Implikasi}

Berdasarkan kesimpulan dari penelitian ini, pembelajaran Bahasa Indonesia dengan menggunakan Media Film dapat memberikan perubahan yang bermanfaat terhadap keterampilan menulis narasi, dan dapat menjadi salah satu alternatif yang dapat digunakan dalam merencanakan program pengajaran Bahasa Indonesia. Pendekatan ini dapat memberikan peluang kepada siswa agar dapat mengemukakan dan membahas suatu masalah bersama dan dapat bekerja sama untuk merumuskan masalah, memiliki motivasi yang tinggi karena didorong dan didukung oleh teman sebayanya, menghargai pendapat teman, membentuk hubungan persahabatan dan berfikir kritis, serta bertanggung jawab atas teman sekelompoknya, menekankan pada tujuan kelompok dan keberhasilan kelompok.

Dengan menggunakan Media Film siswa dilibatkan secara aktif, dan akan sangat membantu keefektifan proses pembelajaran dalam penyampaian pesan dan isi pelajaran Konsep Bahasa Indonesia dapat sampai dengan mudah pada siswa. Oleh karena itu, pembelajaran Bahasa Indonesia dengan menggunakan pembelajaran Media Film perlu diberikan kepada siswa untuk meningkatkan keterampilan menulis narasi. 


\section{B. Saran}

1. Bagi Guru

Disarankan untuk menjadikan pembelajaran Bahasa Indonesia dengan menggunakan Media Film sebagai bagian dari proses belajar mengajar Bahasa Indonesia , sehingga memotivasi siswa agar lebih menyukai pelajaran Bahasa Indonesia dan tidak merasa bosan, sehingga dapat berpengaruh terhadap keterampilan menulis narasi siswa Sekolah Dasar.

\section{Bagi Siswa}

Dengan menggunakan Media Film siswa akan mampu meningkatkan keterampilan menulis narasi, karena Media Film ini sangat efektif dan komunikatif sehingga memudahkan siswa dalam dalam pembelajaran berlangsung.

\section{Bagi Orang Tua}

Diharapkan Orang tua terus memperhatikan dan mendukung kegiatan anak dirumah.

\section{DAFTAR PUSTAKA}

Abidin, Yunus, Pembelajaran Bahasa Berbasis Pendidikan Karakter, Bandung:PT.Refika aditama, 2015.

Andri, Wicaksono, Menulis Kreatif Sastra dan Beberapa Model Pembelajaran, Garudhawaca, 2014.

Arikuntoro, Suharsimi, Prosedur Penelitian Suatu Pendekatan Praktik. Jakarta:Rineka Cipta, 2010.

Arsyad Azhar, Media Pembelajaran, Jakarta: Rajawali Pers, 2015.

Astuti, Widi Yanuarita, Pengaruh Penggunaan Media Film Animasi Terhadap

Atmazaki, Kiat Kiat Mengarang dan Menyunting, Padang: Visigraf, 2006.

Desmita, Psikologi Perkembangan Peserta Didik, Bandung: PT Remaja Rosdakarya, 2009.

Djamarah, Bahri Syairful dan Aswan Zain, Strategi Belajar Mengajar, Jakarta: PT.Rineka Cipta, 2006.

Drs. Rudi Susilana, M.Si. Media Pembelajaran, Bandung: CV Wacana Prima, 2007. Frutescen, Donna, Pengaruh Penggunaan Media Film Kartun Cerita Rakyat Terhadap Kemampuan

Keraf, Gorys, Argumentasi dan Narasi, Jakarta: Gramedia Pustaka Utama, 2010. 
Kurtanto, M Ninik, Cermat dalam berbahasa Teliti dalam Berpikir, Jakarta: Mitra Wacana Media, 2008.

Miarso, Yusufhadi dkk, Teknologi Komunikasi Pendidikan, Jakarta: CV Rajawali, 1984.

Poter de Boby, Quantum Learning, Bandung: Kaifa, 2002.

Soemarjadi, Pendidikan Keterampilan, Jakarta: Departemen Pendidikan dan Kebudayaan, 1991.

Sudjana, Nana, Dasar - Dasar Proses Belajar Mengajar, Bandung: Sinar Baru Algensindo, 1995.

Tarigan, Guntur Herry, Menulis Sebagai Suatu Keterampilan Berbahasa, Bandung: Angkasa, 1986.

Wati, Rima Ega, Ragam Media Pembelajaran, Jakarta: Kata Pena, 2016.

Zulela, Terampil Menulis di Sekolah Dasar, Tangerang: Pustaka Mandiri, 2013. 